\title{
High levels of anti-inflammatory and pro-resolving lipid mediators lipoxins and resolvins and declining docosahexaenoic acid levels in human milk during the first month of lactation
}

\author{
Gisela Adrienne Weiss ${ }^{1,2,3}$, Heinz Troxler ${ }^{1}$, Glynis Klinke ${ }^{1,2}$, Daniela Rogler ${ }^{4}$, Christian Braegger ${ }^{4}$ \\ and Martin Hersberger ${ }^{1,2^{*}}$
}

\begin{abstract}
Background: The fatty acid mixture of human milk is ideal for the newborn but little is known about its composition in the first few weeks of lactation. Of special interest are the levels of long-chain PUFAs (LCPUFAs), since these are essential for the newborn's development. Additionally, the LCPUFAs arachidonic acid (AA), eicosapentaenoic acid (EPA) and docosahexaenoic acid (DHA) are precursors for lipid mediators which regulate inflammation.
\end{abstract}

Methods: We determined the composition of 94 human milk samples from 30 mothers over the first month of lactation for fatty acids using GC-MS and quantified lipid mediators using HPLC-MS/MS.

Results: Over the four weeks period, DHA levels decreased, while levels of $ү \mathrm{C} 18: 3$ and aC18:3 steadily increased. Intriguingly, we found high concentrations of lipid mediators and their hydroxy fatty acid precursors in human milk, including pro-inflammatory leukotriene B4 (LTB4) and anti-inflammatory and pro-resolving lipoxin A4 (LXA4), resolvin D1 (RvD1) and resolvin E1 (RvE1). Lipid mediator levels were stable with the exception of two direct precursors.

Conclusions: Elevated levels of DHA right after birth might represent higher requirements of the newborn and the high content of anti-inflammatory and pro-resolving lipid mediators and their precursors may indicate their role in neonatal immunity and may be one of the reasons for the advantage of human milk over infant formula.

Keywords: Human milk, Omega-3 fatty acids, DHA, EPA, 17-HDHA, 18-HEPE, 15-HETE, Resolvins, Lipoxins, Leukotrienes

\section{Background}

Human milk fat is the main energy source for the breast-fed newborn and provides specific fatty acids that are required for the newborn's development. The fatty acid composition of human milk has been assessed in several studies showing differences between term and preterm milk [1-5] and the influence of diet on the fatty acid composition [6-8]. There is also indication for a

\footnotetext{
* Correspondence: Martin.Hersberger@kispi.uzh.ch

'Clinical Chemistry and Biochemistry, Children's Research Center, University Children's Hospital Zurich, Zurich, Switzerland

${ }^{2} Z$ Zurich Center for Integrative Human Physiology, University of Zurich, Zurich, Switzerland

Full list of author information is available at the end of the article
}

change in fatty acid composition over the lactation period $[5,9-18]$.

Especially, LCPUFAs fulfill several essential functions in the newborns. For example, the omega-6 LCPUFA AA and the omega-3 LCPUFA DHA are crucial for brain and nervous system development $[19,20]$, the visual system [21] and for early human growth in general [22]. In addition, the fatty acid profile of human milk has been associated with the development of atopy and with allergic diseases in children [23-26].

The supply of LCPUFAs by human milk to the newborn determines the fatty acid composition of several lipid compartments including plasma lipids and the 
cellular membrane [27]. The fatty acid composition of the membrane influences not only membrane properties but also immune-regulatory processes through the metabolization of free and membrane bound LCPUFAs to lipid mediators [28]. These lipid mediators are signaling molecules that initiate and resolve inflammation and they derive from oxygenation of the omega- 6 fatty acid AA and the two omega-3 fatty acids DHA and EPA [29,30]. Oxygenation of AA, DHA and EPA occurs in a concerted action of lipoxygenases, cyclooxygenases and cytochrome-P-450 dependent oxygenases to result in the pro-inflammatory leukotrienes and the anti-inflammatory lipoxins from AA and resolvins and protectins from DHA and EPA [29-34]. Apart from being anti-inflammatory, lipoxins, resolvins and protectins also initiate inflammation-resolving actions like recruitment of nonphlogistic monocytes and clearance of apoptotic polymorphonuclear neutrophils by macrophages [35-37]. Due to their potent immune-regulatory functions, these lipid mediators are thought to play a role in chronic inflammatory diseases like atherosclerosis, rheumatoid arthritis and inflammatory bowel disease [31,38-40]. We therefore surmised that a supply of anti-inflammatory and pro-resolving lipid mediators to the newborn by breast milk could be one of the explanations for the lower incidence of intestinal inflammation in breast-fed compared to formula-fed infants [41,42].

Only limited information is available on the fatty acid composition of human milk over the first few weeks of lactation [15-18], and the presence of leukotrienes, lipoxins and resolvins in human milk has not been investigated yet. In this study, we present the milk fatty acid profile and the profile for selected bioactive lipid mediators and their precursors in human milk over the first month of lactation.

\section{Results}

Quantification of fatty acid composition in human milk Thirteen fatty acids containing 16 to 24 carbon atoms (Table 1 and Figure 1) were analysed and quantified in human milk with a specific and selective GC-MS method. For each analyte, the calibration was linear with $\mathrm{R}^{2}>0.98$ and the observed fatty acid concentrations in breast milk were within the working range (See Additional file 1: Table S1). Intra-assay coefficients of variation are stated in (Additional file 1: Table S1).

\section{Fatty acid composition of human milk over the first month of lactation}

The lactational age of the collected human milk samples ranged from 1 to 30 days postpartum. For statistical analysis, the samples were divided into six groups according to their lactational age (Table 2). The major fatty acids in human milk were C18:1, C16:0, C18:2 and C18:0 in descending order. Other fatty acids were
Table 1 Fatty acids analyzed in human milk

\begin{tabular}{lll}
\hline State of saturation & Fatty acid & $\begin{array}{l}\text { Lipid number } \\
(\boldsymbol{C}: D)^{\mathbf{a}}\end{array}$ \\
\hline Saturated & Palmitic acid & $\mathrm{C} 16: 0$ \\
& Stearic acid & $\mathrm{C} 18: 0$ \\
& Arachidic acid & $\mathrm{C} 20: 0$ \\
& Behenic acid & $\mathrm{C} 22: 0$ \\
& Lignoceric acid & $\mathrm{C} 24: 0$ \\
Monounsaturated & Palmitoleic acid & $\mathrm{C} 16: 1$ \\
& Oleic acid & $\mathrm{C} 18: 1$ \\
Omega-6 polyunsaturated & Linoleic acid & $\mathrm{C} 18: 2$ \\
& Y-Linolenic acid & $\mathrm{\gamma C18:3}$ \\
& Arachidonic acid & $\mathrm{C} 20: 4$ \\
Omega-3 polyunsaturated & a-Linolenic acid & $\mathrm{aC} 18: 3$ \\
& Eicosapentaenoic acid & $\mathrm{C} 20: 5$ \\
& Docosahexaenoic acid & $\mathrm{C} 22: 6$
\end{tabular}

${ }^{\mathrm{a}} C$, number of carbon atoms; $D$, number of double bonds

present with quantities lower than $5 \%$ of total fatty acids. The relative content was stable over the first month of lactation for the saturated fatty acids C16:0 to C22:0. Only C24:0 showed a significant decrease (Table 2). The amounts of the monounsaturated fatty acids C16:1 and C18:1 were stable over the observed time period. In contrast, the amount of most PUFAs changed over time (Figure 2). The amount of DHA decreased to approximately half of the initial quantity $(\mathrm{p}<0.0001$, Table 2$)$, while its precursor $\alpha \mathrm{C} 18: 3$ increased over the same period. Similarly, the amount of AA showed a trend to decrease over time $(p=0.094)$ while its precursor $\gamma C 18: 3$ increased. Albeit these changes in the concentration of the PUFAs, the ratio of omega- $6(\mathrm{C} 18: 2, \gamma \mathrm{C} 18: 3, \mathrm{AA})$ to omega-3 ( $\alpha \mathrm{C} 18: 3, \mathrm{EPA}, \mathrm{DHA})$ fatty acids in human milk did not change significantly over the first four weeks of lactation.

\section{Quantification of selected lipid mediators and precursors in human milk}

To determine the concentration of the selected lipid mediators in human breast milk, a HPLC-MS/MS method was developed analyzing LTB4, LXA4, RvE1 and RvD1 and the four hydroxy fatty acids 17-hydroxydocosahexaenoic acid (17-HDHA), 18-hydroxyeicosapentaenoic acid (18-HEPE), 15-hydroxyeicosatetraenoic acid (15-HETE) and 12-hydroxyeicosatetraenoic acid (12HETE) (Figures 3 and 4). For each compound, several transitions were scanned (See Addtional file 1: Table S2) and one transition per analyte was selected as quantifier ion. For each lipid mediator and hydroxy fatty acid, the fragmentation pattern of the analyte from human milk was comparable to the fragmentation pattern of the corresponding standard substance (See Additional file 2: Figure 


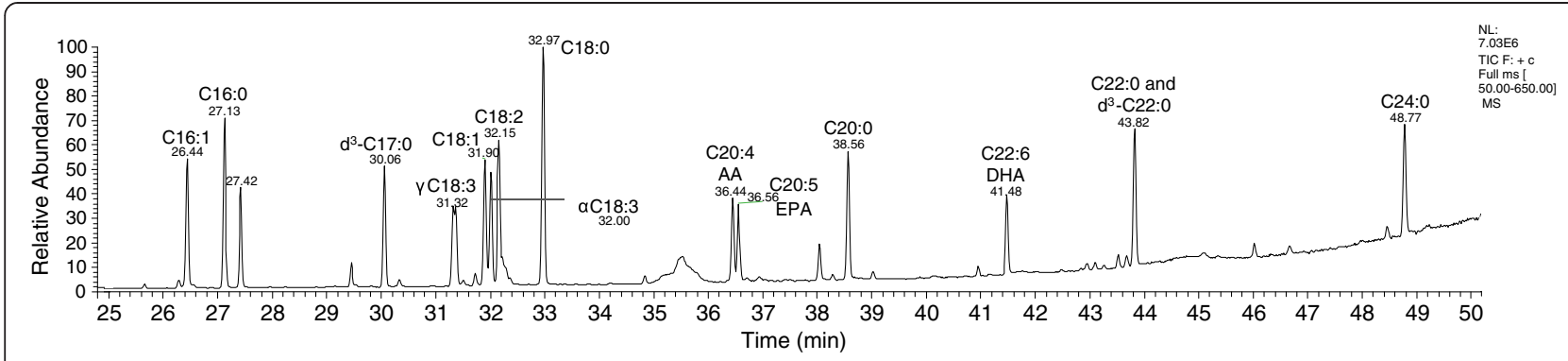

Figure 1 Gas-chromatogram of fatty acid standard substances. Fatty acids in standard mixture were methylated according to the sample preparation procedure prior to injection into the GC-MS system. For nomenclature of the fatty acids see Table 1.

Table 2 Total fatty acid composition (\%) of human milk over time of lactation

\begin{tabular}{|c|c|c|c|c|c|c|c|c|}
\hline \multirow[t]{5}{*}{ Fatty acid } & \multicolumn{6}{|c|}{ Time of lactation (days after birth) } & \multirow[t]{5}{*}{$\mathrm{R}^{2}$} & \multirow[t]{5}{*}{$P$} \\
\hline & $1-5$ & $6-10$ & $11-15$ & $16-20$ & $21-25$ & $26-30$ & & \\
\hline & $\mathrm{N}=15$ & $\mathrm{~N}=27$ & $\mathrm{~N}=\mathbf{2 3}$ & $\mathrm{N}=16$ & $\mathrm{~N}=6$ & $\mathrm{~N}=7$ & & \\
\hline & M & M & M & M & M & M & & \\
\hline & SD & SD & SD & SD & SD & SD & & \\
\hline \multirow[t]{2}{*}{ C16:0 } & 23.96 & 20.75 & 21.96 & 21.95 & 21.90 & 21.92 & 0.12 & 0.63 \\
\hline & 3.47 & 2.41 & 2.55 & 2.59 & 2.60 & 4.02 & & \\
\hline \multirow[t]{2}{*}{ C18:0 } & 6.91 & 6.06 & 7.73 & 7.34 & 6.85 & 7.64 & 0.23 & 0.37 \\
\hline & 1.59 & 1.31 & 1.90 & 1.69 & 0.67 & 1.36 & & \\
\hline \multirow[t]{2}{*}{ C20:0 } & 0.17 & 0.11 & 0.15 & 0.14 & 0.12 & 0.12 & 0.36 & 0.10 \\
\hline & 0.06 & 0.03 & 0.04 & 0.05 & 0.03 & 0.03 & & \\
\hline \multirow[t]{2}{*}{ C22:0 } & 0.22 & 0.13 & 0.15 & 0.12 & 0.13 & 0.17 & 0.16 & 0.27 \\
\hline & 0.18 & 0.04 & 0.06 & 0.04 & 0.04 & 0.03 & & \\
\hline \multirow[t]{2}{*}{$C 24: 0$} & 0.29 & 0.17 & 0.20 & 0.16 & 0.14 & 0.18 & 0.48 & 0.011 \\
\hline & 0.12 & 0.07 & 0.10 & 0.09 & 0.05 & 0.05 & & \\
\hline \multirow[t]{2}{*}{ C16:1 } & 3.35 & 4.55 & 3.66 & 4.30 & 4.27 & 3.67 & 0.02 & 0.74 \\
\hline & 0.87 & 1.35 & 1.17 & 1.81 & 1.21 & 0.89 & & \\
\hline \multirow[t]{2}{*}{ C18:1 } & 46.29 & 48.21 & 45.76 & 44.92 & 46.26 & 43.96 & 0.46 & 0.51 \\
\hline & 5.42 & 3.94 & 5.28 & 3.80 & 5.17 & 2.50 & & \\
\hline \multirow[t]{2}{*}{ C18:2 } & 14.42 & 16.10 & 16.58 & 17.16 & 16.72 & 18.43 & 0.83 & 0.13 \\
\hline & 3.09 & 3.24 & 3.97 & 3.37 & 3.45 & 2.80 & & \\
\hline \multirow[t]{2}{*}{ YC18:3 } & 0.09 & 0.10 & 0.10 & 0.11 & 0.11 & 0.13 & 0.81 & 0.040 \\
\hline & 0.03 & 0.02 & 0.04 & 0.04 & 0.02 & 0.02 & & \\
\hline \multirow[t]{2}{*}{ C20:4 (AA) } & 2.09 & 1.82 & 1.56 & 1.79 & 1.49 & 1.48 & 0.73 & 0.094 \\
\hline & 0.96 & 0.91 & 0.62 & 0.83 & 0.41 & 0.49 & & \\
\hline \multirow[t]{2}{*}{ aC18:3 } & 1.07 & 1.04 & 1.41 & 1.34 & 1.47 & 1.82 & 0.85 & 0.0024 \\
\hline & 0.44 & 0.23 & 0.62 & 0.58 & 0.33 & 0.48 & & \\
\hline \multirow[t]{2}{*}{ C20:5 (EPA) } & 0.08 & 0.06 & 0.06 & 0.07 & 0.07 & 0.07 & 0.06 & 0.77 \\
\hline & 0.02 & 0.02 & 0.03 & 0.01 & 0.02 & 0.01 & & \\
\hline \multirow[t]{2}{*}{ C22:6 (DHA) } & 1.15 & 0.99 & 0.79 & 0.71 & 0.59 & 0.56 & 0.96 & $<0.000$ \\
\hline & 0.42 & 0.33 & 0.25 & 0.32 & 0.11 & 0.22 & & \\
\hline \multirow[t]{2}{*}{ n6/n3 } & 7.58 & 8.92 & 8.31 & 9.47 & 8.81 & 8.27 & 0.12 & 0.59 \\
\hline & 1.73 & 2.40 & 1.50 & 3.11 & 2.53 & 1.00 & & \\
\hline
\end{tabular}




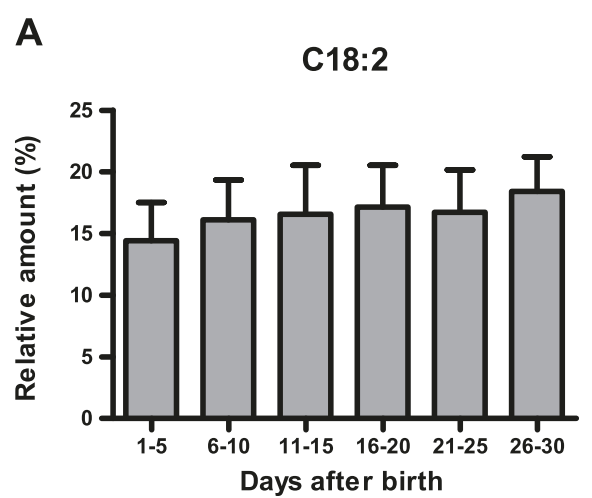

C

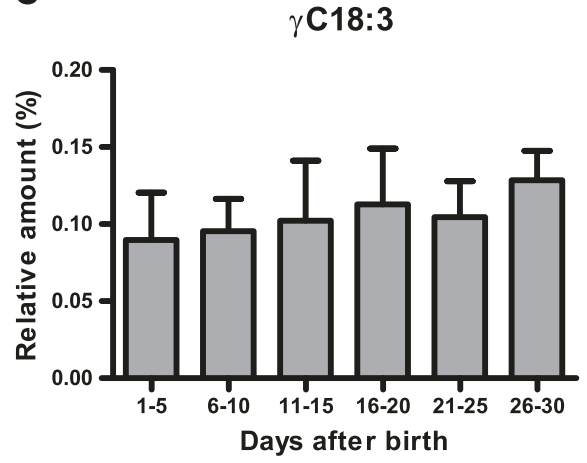

E

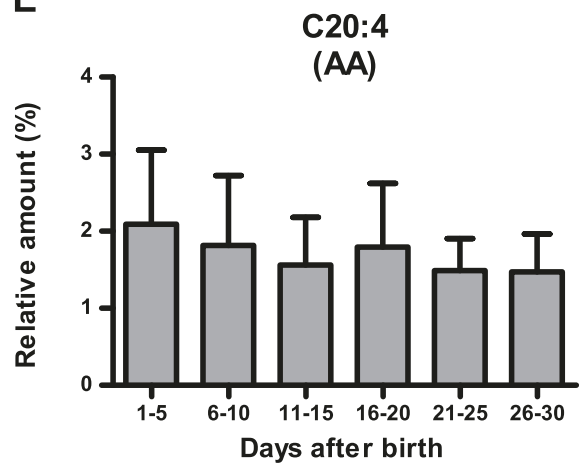

B

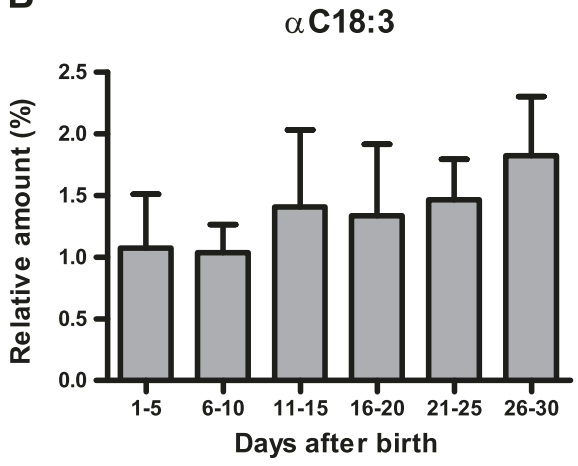

D

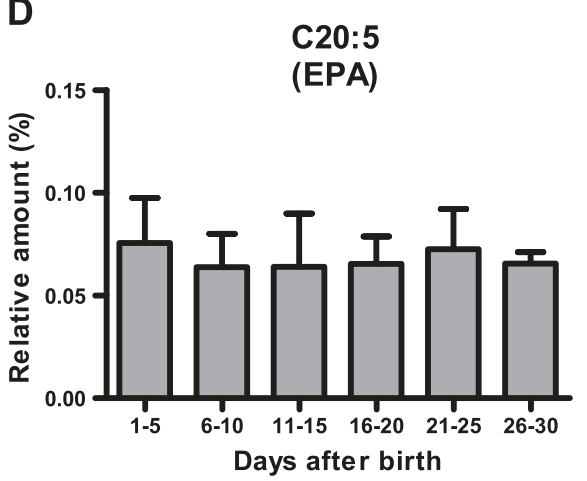

$\mathbf{F}$

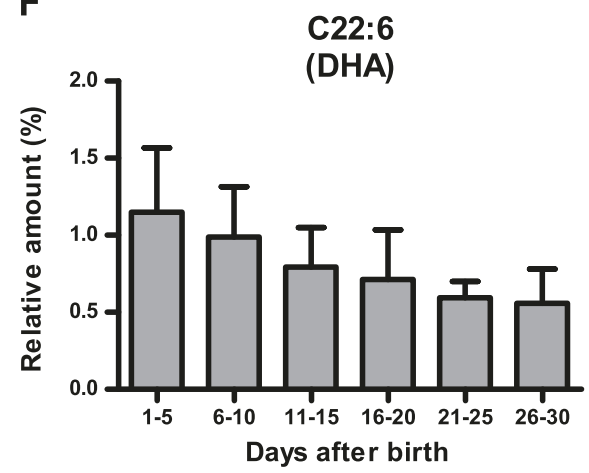

Figure 2 Changes in omega- 6 and omega- 3 fatty acids in human milk over the first month of lactation. Relative amount of the omega- 6 PUFA (E) AA (C20:4) and its precursors (A) C18:2 and (C) үC18:3. Relative amount of the omega-3 PUFA (F) DHA (C22:6) and its precursors (D) aC18:3 and (B) EPA (C20:5). For an overview on PUFA fatty acid biosynthesis see Figure 3.

S1, and Additional file 3: Figure S2). For each analyte, the calibration was linear with $\mathrm{R}^{2}>0.98$ and the observed lipid mediator concentrations in breast milk were within the working range. Intra-assay coefficients of variation are stated in (Additional file 1: Table S2).

\section{Lipid mediator concentrations of human milk over the} first month of lactation

The breast milk concentration of the lipid mediators LTB4, LXA4, RvE1 and RvD1 showed mean values (and ranges) of $9 \mathrm{ng} / \mathrm{ml}$ (0.01 to $24.5 \mathrm{ng} / \mathrm{ml})$ for LTB4, $21 \mathrm{ng} /$ $\mathrm{ml}(0.1$ to $54.1 \mathrm{ng} / \mathrm{ml})$ for LXA4, $6 \mathrm{ng} / \mathrm{ml}(0.03$ to 41.5 $\mathrm{ng} / \mathrm{ml})$ for RvE1 and $10 \mathrm{ng} / \mathrm{ml}(0.01$ to $44.5 \mathrm{ng} / \mathrm{ml})$ for RvD1, and was stable over the period of one month for all lipid mediators (Table 3). The mean concentrations of the precursor hydroxy fatty acids were higher than the concentrations of the more bioactive forms with the exception of 18-HEPE, which was observed at similar concentrations to the resulting lipid mediator RvE1 at the beginning of lactation. Over the observed four weeks of lactation, 18-HEPE increased in concentration, although not significantly $(\mathrm{p}=0.063)$. In contrast, the 


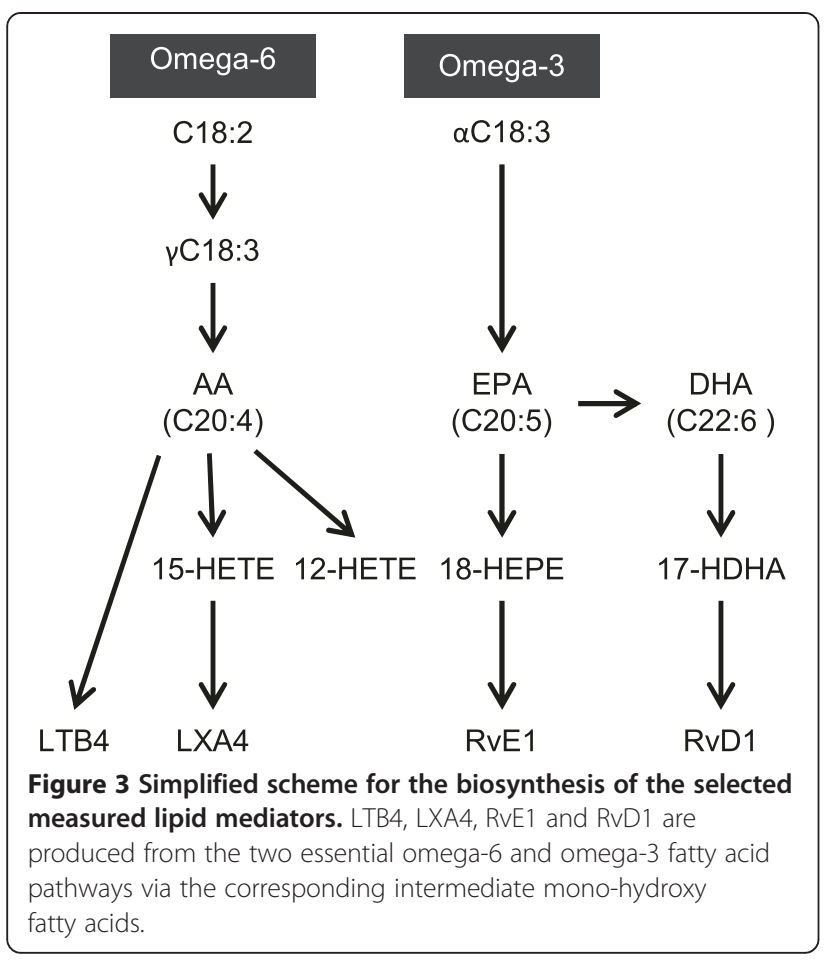

17-HDHA content of human breast milk decreased. It was more than three times higher in the first five days postpartum than three weeks postpartum (Figure 5), which followed the change in DHA content of the human breast milk. The concentrations of 12-HETE and 15-HETE were stable over the observed time period.

\section{Discussion}

In this study, we examined the fatty acid and the derived lipid mediator profiles of human breast milk over the first month of lactation. While most of the fatty acids showed stable concentrations over the four weeks of lactation, the concentrations of the omega- 6 fatty acid AA and of the omega-3 fatty acid DHA decreased over time. Concomitantly, the amount of the precursor fatty acids for both of these very long-chain PUFAs increased. Human breast milk also contains a considerable amount of lipid mediators and its precursor hydroxy fatty acids. While we did not observe a change in concentration for the lipid mediators over the investigated lactation period, the DHA metabolite 17-HDHA decreased in parallel to the DHA concentration (See Additional file 1: Table S3).

The most surprising finding of this study was the high concentration of bioactive lipid mediators and their precursors in human milk. The levels of these analytes in human milk have not been reported so far. All of the investigated lipid mediators LTB4, LXA4, RvE1 and RvD1 were found at considerable concentrations, which were higher than the concentrations reported for plasma of healthy individuals. While human breast milk contains in average $8 \mathrm{ng} / \mathrm{ml}$ of the pro-inflammatory LTB4, the level for LTB4 was reported to be 100 times lower in plasma with concentrations of approximately $34 \mathrm{pg} / \mathrm{ml}$ [43]. Similarly, the concentration for the anti-inflammatory lipid mediators is higher in human breast milk. While breast milk contains in average $18 \mathrm{ng} / \mathrm{ml} \mathrm{LXA4,}$ the plasma levels were reported to be 100 times lower ranging from 10 to $26 \mathrm{pg} / \mathrm{ml}$ [44]. Also, RvD1 levels are

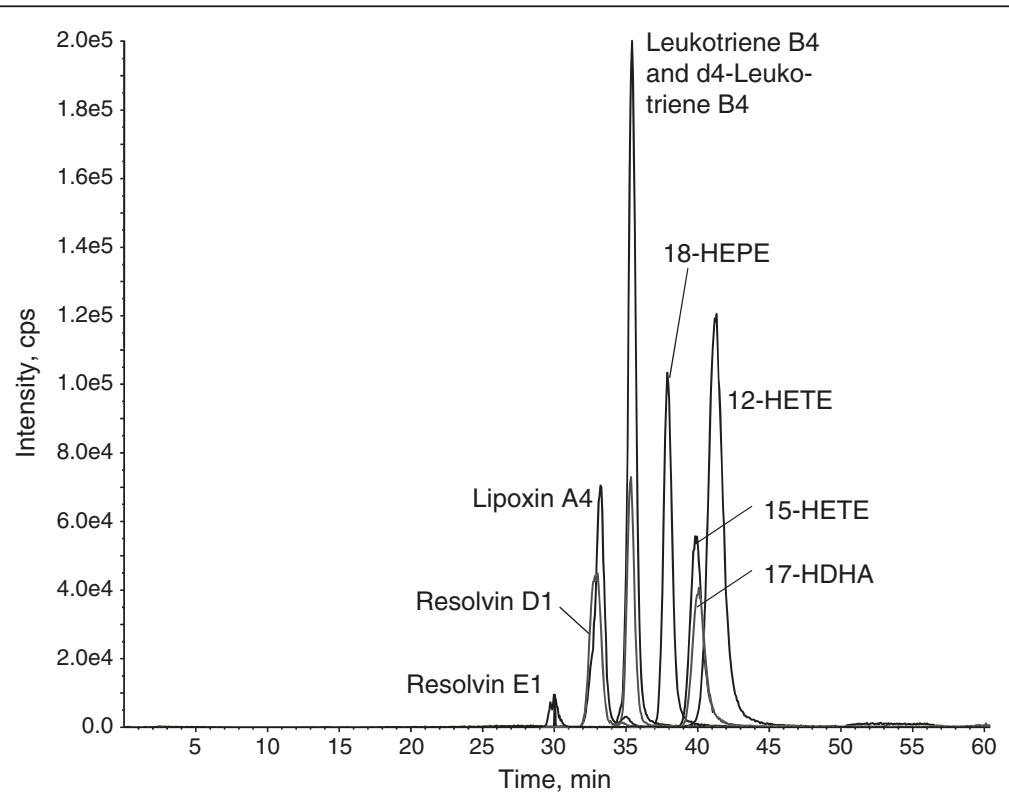

Figure 4 Chromatogram of lipid mediators and related precursor hydroxy fatty acids. $5 \mu \mathrm{l}$ of a $0.1 \mathrm{ng} / \mu \mathrm{l}$ standard mixture was injected into the HPLC-MS/MS system. Cps, counts per second. 
Table 3 Concentration $(\mathrm{ng} / \mathrm{ml})$ of lipid mediators and precursors in human milk over time of lactation

\begin{tabular}{|c|c|c|c|c|c|c|c|c|}
\hline \multirow[t]{5}{*}{ Compound } & \multicolumn{6}{|c|}{ Time of lactation (days after birth) } & \multirow[t]{5}{*}{$\mathrm{R}^{2}$} & \multirow[t]{5}{*}{$\mathbf{P}$} \\
\hline & $1-5$ & $6-10$ & $11-15$ & $16-20$ & $21-25$ & $26-30$ & & \\
\hline & $\mathrm{N}=11-14$ & $\mathrm{~N}=\mathbf{2 0 - 2 3}$ & $\mathrm{N}=20-21$ & $\mathrm{~N}=13-14$ & $\mathrm{~N}=6$ & $\mathrm{~N}=6-7$ & & \\
\hline & M & M & M & M & M & M & & \\
\hline & SD & SD & SD & SD & SD & SD & & \\
\hline \multirow[t]{2}{*}{ LTB4 } & 9.48 & 10.01 & 10.19 & 8.47 & 9.31 & 7.78 & \multirow[t]{2}{*}{0.51} & \multirow[t]{2}{*}{0.44} \\
\hline & 8.59 & 4.43 & 5.28 & 6.31 & 5.64 & 3.34 & & \\
\hline \multirow[t]{2}{*}{ LXA4 } & 15.55 & 25.02 & 22.11 & 16.65 & 19.53 & 22.04 & \multirow[t]{2}{*}{0.02} & \multirow[t]{2}{*}{0.19} \\
\hline & 16.87 & 14.68 & 13.11 & 14.06 & 10.11 & 12.60 & & \\
\hline \multirow[t]{2}{*}{ RVE1 } & 4.24 & 5.23 & 8.15 & 4.60 & 12.57 & 5.67 & \multirow[t]{2}{*}{0.19} & \multirow[t]{2}{*}{0.13} \\
\hline & 5.76 & 3.91 & 11.45 & 4.08 & 15.20 & 5.65 & & \\
\hline \multirow[t]{2}{*}{ RvD1 } & 9.42 & 12.46 & 12.37 & 6.48 & 9.53 & 9.99 & \multirow[t]{2}{*}{0.08} & \multirow[t]{2}{*}{0.58} \\
\hline & 11.68 & 7.34 & 9.28 & 6.24 & 4.64 & 5.06 & & \\
\hline \multirow[t]{2}{*}{ 17-HDHA } & 53.38 & 40.73 & 34.04 & 22.72 & 14.76 & 28.27 & \multirow[t]{2}{*}{0.71} & \multirow[t]{2}{*}{0.0035} \\
\hline & 37.80 & 25.41 & 22.61 & 20.94 & 6.61 & 25.50 & & \\
\hline \multirow[t]{2}{*}{ 18-HEPE } & 7.20 & 7.29 & 8.99 & 6.28 & 9.80 & 8.30 & \multirow[t]{2}{*}{0.18} & \multirow[t]{2}{*}{0.063} \\
\hline & 5.02 & 2.63 & 3.92 & 4.54 & 6.60 & 3.29 & & \\
\hline \multirow[t]{2}{*}{ 15-HETE } & 28.38 & 24.19 & 26.90 & 25.35 & 22.80 & 26.04 & \multirow[t]{2}{*}{0.22} & \multirow[t]{2}{*}{0.60} \\
\hline & 16.44 & 12.86 & 11.72 & 17.85 & 8.33 & 19.65 & & \\
\hline \multirow[t]{2}{*}{ 12-HETE } & 43.90 & 38.46 & 36.71 & 28.12 & 28.75 & 23.63 & \multirow[t]{2}{*}{0.95} & \multirow[t]{2}{*}{0.39} \\
\hline & 26.61 & 29.11 & 15.99 & 19.37 & 15.80 & 11.55 & & \\
\hline
\end{tabular}

$\mathrm{M}$, mean; SD, standard deviation; $\mathrm{R}^{2}$, coefficient of determination of linear trendline; $\mathrm{P}, \mathrm{p}$-value for linear trend (ANOVA)

100 times lower in plasma than in human breast milk with $31 \mathrm{pg} / \mathrm{ml} \mathrm{[45]} \mathrm{and} 9 \mathrm{ng} / \mathrm{ml}$, respectively. The levels for RvE1 are 10 times higher in human breast milk than in plasma with $6 \mathrm{ng} / \mathrm{ml}$ and 0.1 to $0.4 \mathrm{ng} / \mathrm{ml}$ of $\mathrm{RvE} 1$, respectively [33]. There is also a 10-100 times increase in the concentration of the precursors for these lipid mediators. While we detected 12-HETE, 15-HETE, 18HEPE and 17-HDHA mean concentrations in human breast milk in the range of $5-40 \mathrm{ng} / \mathrm{ml}$, these hydroxy fatty acids were measured in the low nanomolar range in human whole blood with concentrations ranging from
0.1 to $4.10 \mathrm{ng} / \mathrm{ml}[45,46]$. Thus, there seems to be an enrichment of the lipid mediators and its precursors in human breast milk, similar to the enrichment previously observed for some of the prostaglandins [47].

Our data also suggest a preferred accumulation of anti-inflammatory and pro-resolving lipid mediators in human milk as seen by the bioactive products of AA. This fatty acid can be converted into pro- and antiinflammatory lipid mediators like LTB4 and LXA4, respectively [48]. In human milk, the average content of anti-inflammatory LXA4 is double as high as for the

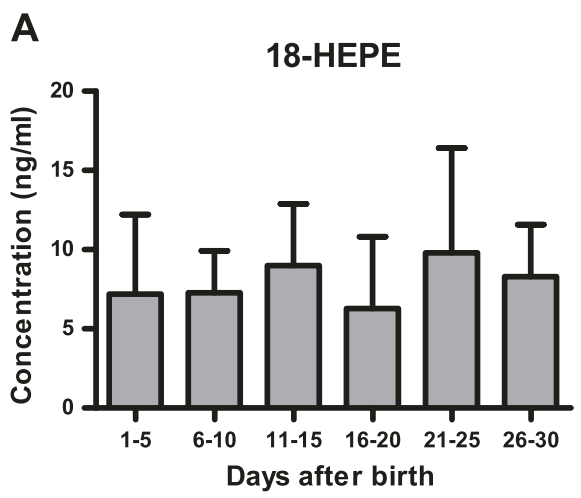

B

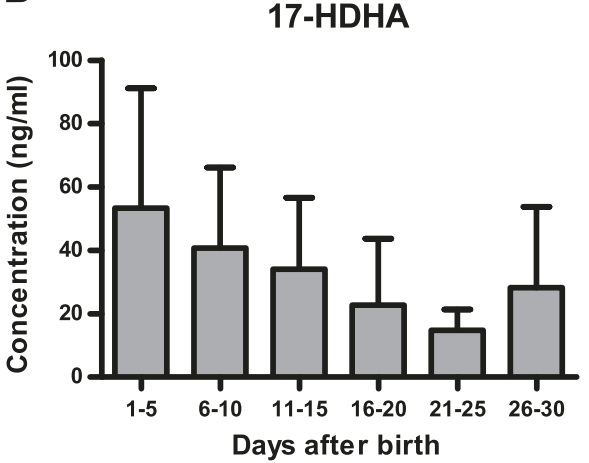

Figure $\mathbf{5}$ Changes in the concentration of the precursor hydroxy fatty acids over the first month of lactation. Concentrations of (A) 18-HEPE (precursor of RVE1) and (B) 17-HDHA (precursor of RVD1) were measured in human milk over the first month of lactation. 
pro-inflammatory LTB4, while in human whole blood the concentration of LXA4 seems to be lower than the concentration of LTB4 $[43,44]$. In addition, there are high concentrations of the precursor hydroxy fatty acids for the anti-inflammatory and pro-resolving lipid mediators present in human breast milk. At least some of the precursors also have potent anti-inflammatory and proresolving effects, which may derive from a direct effect or through its metabolism to the lipid mediators.

Several studies have shown that the lipid mediators LXA4, RvE1 and RvD1 have potent anti-inflammatory and pro-resolving effects in experimental mouse models of intestinal colitis [49-53]. In addition, also 17-HDHA, the precursor for RvD1, was shown to reduce inflammation in dextran sulfate sodium induced colitis in mice [52]. It is therefore tempting to speculate that these high levels of lipid mediators and their precursors in human milk might affect the immune regulation of the gastrointestinal tract in the newborn. In this line, the concentrations measured in human breast milk for RvD1 and LXA4 meet the concentrations necessary to effect human leukocytes in an anti-inflammatory and pro-resolving manner $[54,55]$. For example, LXA4 and RvE1 were shown to suppress neutrophil infiltration and to promote phagocytosis of bacteria and apoptotic neutrophils by macrophages in the nanomolar range $[33,35,56,57]$. In similar concentrations, analogs of LXA4 were able to reduce pathogen-induced interleukin- 8 production in intestinal [58] and bronchial human epithelial cells [59], which resulted in inhibited neutrophil recruitment, and thus in reduced inflammation. Hence, the measured breast milk concentrations of anti-inflammatory and pro-resolving lipid mediators are within the physiological range reported to inhibit inflammatory processes, and therefore, might lower inflammation in the newborn infant.

The concentrations of the measured lipid mediators did not change over the first month of lactation in contrast to the two precursor hydroxy fatty acids 17HDHA and 18-HEPE. While the concentration of 18HEPE slightly increases during lactation, the concentration of 17-HDHA decreases in parallel to the decrease of its precursor fatty acid DHA. The breast milk concentrations of the lipid mediator products RvE1 and RvD1 do not show the same temporal pattern, which is in agreement with the just in time generation of these inflammatory regulators during an acute inflammation [48]. Similarly, the concentrations of all the lipid mediators investigated in this study are constant in breast milk over the first month of lactation. Hence, an effect of degradation during storage can be excluded, since all samples were stored for the same time period. However, it is not clear why the intermediate precursor fatty acids investigated are present in such high concentrations in human breast milk. Possibly, these fatty acids are supplied as pre-metabolized lipid mediators for a final conversion to the more potent lipid mediators in the newborn's intestine. Considering the high concentration of these anti-inflammatory and pro-resolving hydroxy fatty acids and lipid mediators in human breast milk, we presume a potential role in lowering the overall inflammation in breast-fed infants, suggesting a possible reason for the lower incidence of inflammatory diseases in breastfed compared to formula-fed children [60-62]. In addition, these lipid mediators may be involved in gastrointestinal pain reception in newborns, since RvE1 and RvD1 have been shown to reduce inflammatory pain in mice [63].

The average fatty acid profile found in our study is similar to the fatty acid compositions reported before $[1,5,7,14,23,64]$. Considering the profile over the first month of lactation, the relative content in milk is stable for most fatty acids, while the concentration of specific LCPUFAs changes over this period.

Similar results were found in recent studies in which human milk with equal lactational age was analyzed and which presented the same decrease of DHA and AA over time, while the precursor fatty acids C18:2, $\gamma \mathrm{C} 18: 3$ and $\alpha C 18: 3$ increased during the same period [6,14]. It was previously speculated that the increase in the precursors $\mathrm{C} 18: 2$, $\gamma \mathrm{C} 18: 3$ and $\alpha \mathrm{C} 18: 3$ might compensate for the declining levels of DHA and AA in human breast milk, which may come from the depletion of the maternal DHA stores [65]. Alternatively, the high relative amounts of DHA and AA in the beginning of lactation may well be a mechanism to compensate for the lower absolute fat content of human breast milk in the beginning of lactation $[64,66]$. This may assure a stable supply of DHA and AA to the newborn suggesting a regulation of the fatty acid secretion by the mammary gland, which is not only dependent on the maternal DHA intake and plasma levels.

DHA and AA are important for the neonatal development. Especially DHA has a high abundance in the brain and retina where it is accumulated predominantly in the last trimester of pregnancy and during the first year after birth [67]. Before birth, most of the accumulated DHA is delivered from the mother by transplacental transfer [68]. After birth, human milk is the only exogenous source of DHA for the breast-fed child. The endogenous de novo production of the newborn and the DHA stores in adipose tissue alone are not sufficient to maintain DHA homeostasis [69]. Infants fed formula without DHA showed reduced DHA stores in their tissue six months after birth and showed only half the accumulation rate for DHA in the brain compared to breast-fed infants [70]. At the same time, breast-fed infants further increased their DHA stores also in nonbrain tissues. Hence, the newborn's need for DHA is eminent and elevated DHA levels in human milk right 
after birth may represent the high requirement for DHA at that time.

Preterm infants are born with a lower DHA status, because they did not complete intrauterine DHA accumulation [71]. The importance of DHA for the development is underlined by the higher DHA content of human preterm milk [2] and by the elevated activity of enzymes required for LCPUFA production in preterm infants [72]. This suggests that the fatty acid composition of human milk is part of the natural mechanism to regulate the infant's DHA status.

DHA and AA are on the one hand vital for neuronal and visual functions, and on the other hand pivotal for the neonatal development of the immune system. Several studies confirmed that the DHA status is linked to various immune processes [73-77] and that several LCPUFAs have the potential to influence the immune system. For example, atopic sensitization of the newborn is associated to the $\alpha$-linolenic acid and omega- 3 fatty acid supply [78] and a higher tissue status of omega-3 fatty acids results in reduced inflammation and less tissue injury in a colitis model in mice [79]. The latter was shown in transgenic mice expressing fat-1, the enzyme responsible for the endogenous production of the omega-3 and omega-6 LCPUFAs DHA and AA from the essential PUFAs. As mentioned before, these LCPUFAs are the precursors of the lipid mediators and the metabolism of these LCPUFAs to the corresponding lipid mediators may play a role in the protective effect of the LCPUFAs in innate and adaptive immune responses [80-82]. Hence, our results suggest that human milk may be an important regulator of neonatal immunity by providing not only the precursors, but also the bioactive forms of these lipid mediators.

\section{Conclusions}

We investigated human milk to identify components that are responsible for the beneficial effect of human milk on neonatal health. Our results confirm a considerable amount of DHA and AA in human milk with higher levels in the beginning of lactation. Since the nutrient composition of human milk reflects the ideal mixture to satisfy the newborn's needs, this likely mirrors the neonatal DHA and AA requirements. Moreover, we demonstrate the presence of bioactive lipid mediators in human milk which affect atopy and inflammation and therefore influence neonatal immunity. Our results support an addition of DHA and AA to infant formula which is often done nowadays, but still is not standard practice. The high content of anti-inflammatory lipid mediators and its precursors in human breast milk may indicate the crucial role of lipid mediators in neonatal immunity and may be a reason for the advantage of human breast milk over infant formula.

\section{Methods}

Sample collection and preparation for fatty acid analysis

94 human milk samples were obtained from 30 mothers and the lactational age was recorded. Samples were stored at $-20^{\circ} \mathrm{C}$ for approximately 120 days. Sample preparation for total fatty acid analysis was essentially done according to Moser et al. [83]. $125 \mu \mathrm{l}$ of human milk was diluted 1:2 with ultrapure water (ELGA Purelab Ultra, Labtec Service AG, Wohlen, Switzerland) and subjected to protein precipitation with $1 \mathrm{ml}$ methanol-methylene chloride (3:1, v/v). $20 \mu \mathrm{g} \mathrm{d}$-C17:0 (Cambridge Isotope Laboratories, Inc., Andover, MA, USA) and $0.8 \mu \mathrm{g} \mathrm{d}_{3}-\mathrm{C} 22: 0$ (Dr. Ehrenstorfer $\mathrm{GmbH}$, Augsburg, Germany) were added as internal standards. Fatty acid methyl esters were prepared by the addition of $200 \mu$ lacetyl chloride and subsequent incubation at $75^{\circ} \mathrm{C}$ for one hour. The reaction was neutralized with $4 \mathrm{ml}$ $7 \% \quad \mathrm{~K}_{2} \mathrm{CO}_{3}$, and fatty acid methyl esters were extracted with $2 \mathrm{ml}$ hexane. After centrifugation at $2500 \mathrm{rpm}$ for $20 \mathrm{~min}, 1.6 \mathrm{ml}$ of the hexane layer was dried under nitrogen and redissolved in $280 \mu \mathrm{l}$ heptane for injection into the GC-MS system. Calibration curves were obtained with defatted cow's milk spiked with known concentrations of fatty acid standards, thereby defining the individual working range for each fatty acid (See Additional file 1: Table S1).

\section{GC-MS of fatty acid methyl esters}

One $\mu$ l sample was injected into a Finnigan PolarisQ ion trap GC-MS system (Thermo Quest, Austin, TX, USA). The injector temperature was $280^{\circ} \mathrm{C}$ and fatty acid methyl esters were separated on a 30 m BGB-1701 column (BGB Analytik AG, Boeckten, Switzerland). The initial oven temperature of $50^{\circ} \mathrm{C}$ was hold for $8 \mathrm{~min}$ and then increased gradually by $5^{\circ} \mathrm{C} / \mathrm{min}$ reaching a final temperature of $280^{\circ} \mathrm{C}$. The ion source temperature and transfer line temperature was $230^{\circ} \mathrm{C}$ and $300^{\circ} \mathrm{C}$, respectively. Analytes were detected as positive ions in full scan mode from 50 to $650 \mathrm{~m} / \mathrm{z}$. Specific mass traces were extracted for the quantification of each analyte (See Additional file 1: Table S1). Fatty acids were identified by comparison of retention time and mass spectrum with authentic standards.

\section{Sample preparation for analysis of lipid mediators and their precursors}

85 of the human milk samples were stored at $-20^{\circ} \mathrm{C}$ for approximately 330 days. The analyte extraction method was adapted from Yang et al. [84]. Two volumes of ice cold methanol and $3 \mathrm{ng}$ of deuterated LTB4 $\left(\mathrm{d}_{4}\right.$-LTB4; Enzo Life Sciences AG, Lausen, Switzerland) as internal standard were added to $1 \mathrm{ml}$ human milk. The samples were centrifuged for $20 \mathrm{~min}$ at $2500 \mathrm{rpm}$ and the supernatant was diluted with $5 \mathrm{ml}$ ultrapure water. The 
diluted supernatant was loaded on a C18 solid phase extraction (SPE) column (Grace, Deerfield, IL, USA) prewashed with $5 \mathrm{ml} 90 \%$ methanol and $5 \mathrm{ml} 5 \%$ methanol. After sample loading, the SPE column was washed with $2 \times 5 \mathrm{ml} 5 \%$ methanol and the analytes were eluted with $3 \mathrm{ml} 90 \%$ methanol. The eluate was dried under nitrogen and redissolved in $100 \mu \mathrm{l} 35 \%$ methanol (2 mM ammonium acetate). The sample was filtered with a $0.2 \mu \mathrm{m}$ syringe filter (BGB Analytik AG, Boeckten, Switzerland) and $5 \mu$ l were injected into a HPLC-MS/MS system. Calibration curves were obtained by lipid mediator standard addition to human milk at the concentrations 0 , 15, 30, 45, 60, 75 and $90 \mathrm{ng} / \mathrm{ml}$.

\section{HPLC-MS/MS of lipid mediators and hydroxy fatty acids}

Analytes were separated using a HPLC system (UltiMate ${ }^{\curvearrowleft}$ HPLC, LC Packings, Dionex, Olten, Switzerland) with a C18 column (Luna 3u C18(2) 100A, 150x0.3 mm; Phenomenex, Brechbühler AG, Schlieren, Switzerland). A gradient was run over $10 \mathrm{~min}$ from $35 \%$ to $80 \%$ methanol (2 $\mathrm{mM}$ ammonium acetate) and was kept constant for $25 \mathrm{~min}$ at a flow rate of $4 \mu \mathrm{l} / \mathrm{min}$. The column was rinsed with $100 \%$ methanol and equilibrated with $35 \%$ methanol (2 mM ammonium acetate). Analytes of interest were detected on a Sciex 4000 QTRAP mass spectrometer (AB SCIEX GmbH, Zug, Switzerland) in the negative ion mode. Several transitions per analyte were scanned in multiple reaction monitoring mode and are stated in (Additional file 1: Table S2). The transitions used for quantification were $335 \rightarrow 195$ for LTB4, $351 \rightarrow 115$ for LXA4, $349 \rightarrow 195$ for RvE1, 375 $\rightarrow 233$ for RvD1, 343 $\rightarrow 281$ for 17 -HDHA, $317 \rightarrow 167$ for 18 -HEPE, $319 \rightarrow 175$ for 15 -HETE, $319 \rightarrow 179$ for 12 -HETE and $339 \rightarrow 197$ for $d_{4}$-LTB4. Fragments scanned for the bioactive anti-inflammatory and pro-resolving LXA4, RvE1 and RvD1 were in agreement with prominent product ions reported earlier [33,84-86]. The optimized MS parameters were defined as: Electrospray ionization (ESI), curtain gas $(\mathrm{CUR})=10$, nebulizer gas $(\mathrm{GS} 1)=20$, auxiliary gas $($ GS2 $)=0$, ionspray voltage $($ IS) $=-4500 \mathrm{~V}$, collision gas $(\mathrm{CAD})=$ medium, entrance potential $(\mathrm{EP})=-10 \mathrm{~V}$, cell exit potential $=-11$ to $-5 \mathrm{~V}$, dwell time $=100$ msec. Declustering potential (DP) and collision energy (CE) were optimized individually for each analyte (See Additional file 1: Table S2). Fragmentation patterns for each analyte as standard substance as well as isolated from human milk were obtained by product ion scans at MS parameter settings defined above.

\section{Data analysis}

Statistical analysis was done using Microsoft Office Excel. To estimate the difference between groups, analysis of variance (ANOVA) with subsequent trend analysis was used. All values are presented as mean with standard deviation or as indicated. Two-sided p-values < 0.05 were considered significant.

\section{Additional files}

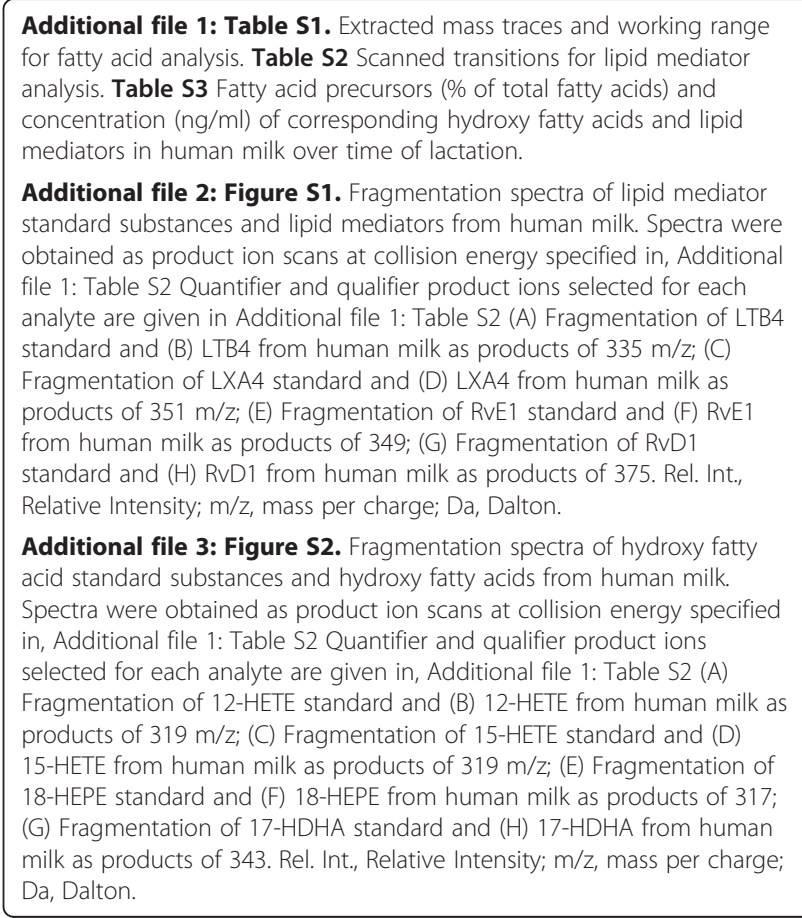

\section{Abbreviations}

12-HETE: 12-hydroxyeicosatetraenoic acid; 15-HETE: 15hydroxyeicosatetraenoic acid; 17-HDHA: 17-hydroxydocosahexaenoic acid; 18-HEPE: 18-hydroxyeicosapentaenoic acid; AA: Arachidonic acid; DHA: Docosahexaenoic acid; EPA: Eicosapentaenoic acid; GC-MS: Gas chromatography mass spectrometry; HPLC-MS/MS: High-performance liquid chromatography tandem mass spectrometry; LCPUFA: Long-chain polyunsaturated fatty acid; LTB4: Leukotriene B4; LXA4: Lipoxin A4; RvD1: Resolvin D1; RvE1: Resolvin E1; SPE: Solid phase extraction.

\section{Competing interests}

The authors declare that they have no competing interests.

\section{Authors' contributions}

GW, DR, CB, MH designed the study and DR and CB collected the human milk samples. GW, HT and GK developed and performed the GC-MS and the LC-MS/MS assays to determine the fatty acid and lipid mediator levels in human milk. GW, HT, GK and MH analyzed the data, and GW and MH wrote the manuscript. All authors read and approved the manuscript.

\section{Acknowledgments}

This work is part of a cooperative project funded by the University Research Priority Program "Integrative Human Physiology".

\section{Author details}

${ }^{1}$ Clinical Chemistry and Biochemistry, Children's Research Center, University Children's Hospital Zurich, Zurich, Switzerland. 'Zurich Center for Integrative Human Physiology, University of Zurich, Zurich, Switzerland. ${ }^{3}$ Institute of Physiology, University of Zurich, Zurich, Switzerland. ${ }^{4}$ Gastroenterology and Nutrition, University Children's Hospital Zurich, Zurich, Switzerland.

Received: 10 May 2013 Accepted: 10 June 2013

Published: 15 June 2013 


\section{References}

1. Kovacs A, Funke S, Marosvolgyi T, Burus I, Decsi T: Fatty acids in early human milk after preterm and full-term delivery. J Pediatr Gastroenterol Nutr 2005, 41:454-459.

2. Bokor S, Koletzko B, Decsi T: Systematic review of fatty acid composition of human milk from mothers of preterm compared to full-term infants. Ann Nutr Metab 2007, 51:550-556.

3. Kilari AS, Mehendale SS, Dangat KD, Yadav HR, Gupta A, Taralekar VS, Joshi SR: Long chain polyunsaturated fatty acids in mothers of preterm babies. J Perinat Med 2010, 38:659-664.

4. Kilari AS, Mehendale SS, Dangat KD, Yadav HR, Kulakarni AV, Dhobale MV, Taralekar VS, Joshi SR: Long chain polyunsaturated fatty acids in mothers and term babies. J Perinat Med 2009, 37:513-518.

5. Luukkainen P, Salo MK, Nikkari T: Changes in the fatty acid composition of preterm and term human milk from 1 week to 6 months of lactation. J Pediatr Gastroenterol Nutr 1994, 18:355-360.

6. Finley DA, Lonnerdal B, Dewey KG, Grivetti LE: Breast milk composition: fat content and fatty acid composition in vegetarians and non-vegetarians. Am J Clin Nutr 1985, 41:787-800.

7. Hoppu U, Isolauri E, Laakso P, Matomaki J, Laitinen K: Probiotics and dietary counselling targeting maternal dietary fat intake modifies breast milk fatty acids and cytokines. Eur J Nutr 2012, 51:211-219.

8. Dunstan JA, Mitoulas LR, Dixon G, Doherty DA, Hartmann PE, Simmer K, Prescott SL: The effects of fish oil supplementation in pregnancy on breast milk fatty acid composition over the course of lactation: a randomized controlled trial. Pediatr Res 2007, 62:689-694.

9. Boersma ER, Offringa PJ, Muskiet FA, Chase WM, Simmons IJ: Vitamin E, lipid fractions, and fatty acid composition of colostrum, transitional milk, and mature milk: an international comparative study. Am J Clin Nutr 1991, 53:1197-1204.

10. Makrides M, Simmer K, Neumann M, Gibson R: Changes in the polyunsaturated fatty acids of breast milk from mothers of full-term infants over 30 wk of lactation. Am J Clin Nutr 1995, 61:1231-1233.

11. Agostoni C, Marangoni F, Bernardo L, Lammardo AM, Galli C, Riva E: Long-chain polyunsaturated fatty acids in human milk. Acta Paediatr Supp/ 1999, 88:68-71.

12. Ribeiro M, Balcao V, Guimaraes H, Rocha G, Moutinho C, Matos C, Almeida C, Casal S, Guerra A: Fatty acid profile of human milk of Portuguese lactating women: prospective study from the 1st to the 16th week of lactation. Ann Nutr Metab 2008, 53:50-56.

13. Clark RM, Ferris AM, Fey M, Brown PB, Hundrieser KE, Jensen RG: Changes in the lipids of human milk from 2 to 16 weeks postpartum. J Pediatr Gastroenterol Nutr 1982, 1:311-315.

14. Wu TC, Lau BH, Chen PH, Wu LT, Tang RB: Fatty acid composition of Taiwanese human milk. Journal of the Chinese Medical Association : JCMA 2010, 73:581-588.

15. Harzer G, Haug M, Dieterich I, Gentner PR: Changing patterns of human milk lipids in the course of the lactation and during the day. Am J Clin Nutr 1983, 37:612-621.

16. Rodkiewicz B, Hardell LI, Pawlikowska-Rojewska B, Tuvemo T: Fatty acid composition of human breast milk. Changes during the first week after delivery. Upsala journal of medical sciences 1981, 86:279-289.

17. Hall B: Uniformity of human milk. Am J Clin Nutr 1979, 32:304-312.

18. Guthrie HA, Picciano MF, Sheehe D: Fatty acid patterns of human milk. J Pediatr 1977, 90:39-41.

19. Ballabriga A: Essential fatty acids and human tissue composition An overview. Acta Paediatr Suppl 1994, 402:63-68.

20. Carlson SE: Long-chain polyunsaturated fatty acids and development of human infants. Acta Paediatr Supp/ 1999, 88:72-77.

21. Jeffrey $B G$, Weisinger $H S$, Neuringer M, Mitchell DC: The role of docosahexaenoic acid in retinal function. Lipids 2001, 36:859-871.

22. Xiang $M$, Zetterstrom $R$ : Relation between polyunsaturated fatty acids and growth. Acta Paediatr Supp/ 1999, 88:78-82.

23. Lowe AJ, Thien FC, Stoney RM, Bennett CM, Hosking CS, Hill DJ, Carlin JB, Abramson MJ, Dharmage SC: Associations between fatty acids in colostrum and breast milk and risk of allergic disease. Clinical and experimental allergy : journal of the British Society for Allergy and Clinical Immunology 2008, 38:1745-1751.

24. Stoney RM, Woods RK, Hosking CS, Hill DJ, Abramson MJ, Thien FC Maternal breast milk long-chain n-3 fatty acids are associated with increased risk of atopy in breastfed infants. Clinical and experimental allergy: journal of the British Society for Allergy and Clinical Immunology 2004, 34:194-200

25. Laitinen K, Hoppu U, Hamalainen M, Linderborg K, Moilanen E, Isolauri E: Breast milk fatty acids may link innate and adaptive immune regulation: analysis of soluble CD14, prostaglandin E2, and fatty acids. Pediatr Res 2006, 59:723-727.

26. Duchen K, Casas R, Fageras-Bottcher M, Yu G, Bjorksten B: Human milk polyunsaturated long-chain fatty acids and secretory immunoglobulin $A$ antibodies and early childhood allergy. Pediatric allergy and immunology: official publication of the European Society of Pediatric Allergy and Immunology 2000, 11:29-39.

27. Calder PC: Fatty acids and immune function: relevance to inflammatory bowel diseases. Int Rev Immunol 2009, 28:506-534.

28. Calder PC: Fatty acids and inflammation: the cutting edge between food and pharma. Eur J Pharmacol 2011, 668(Suppl 1):S50-S58.

29. Shimizu T: Lipid mediators in health and disease: enzymes and receptors as therapeutic targets for the regulation of immunity and inflammation. Annu Rev Pharmacol Toxicol 2009, 49:123-150.

30. Serhan CN, Krishnamoorthy S, Recchiuti A, Chiang N: Nove anti-inflammatory-pro-resolving mediators and their receptors. Curr Top Med Chem 2011, 11:629-647.

31. Hersberger M: Potential role of the lipoxygenase derived lipid mediators in atherosclerosis: leukotrienes, lipoxins and resolvins. Clinical chemistry and laboratory medicine: CCLM / FESCC 2010, 48:1063-1073.

32. Serhan CN, Hong S, Gronert K, Colgan SP, Devchand PR, Mirick G, Moussignac RL: Resolvins: a family of bioactive products of omega-3 fatty acid transformation circuits initiated by aspirin treatment that counter proinflammation signals. J Exp Med 2002, 196:1025-1037.

33. Arita M, Bianchini F, Aliberti J, Sher A, Chiang N, Hong S, Yang R, Petasis $N A$, Serhan CN: Stereochemical assignment, antiinflammatory properties, and receptor for the omega-3 lipid mediator resolvin E1. J Exp Med 2005, 201:713-722.

34. Oh SF, Pillai PS, Recchiuti A, Yang R, Serhan CN: Pro-resolving actions and stereoselective biosynthesis of $18 \mathrm{~S}$ E-series resolvins in human leukocytes and murine inflammation. J Clin Invest 2011, 121:569-581.

35. Godson C, Mitchell S, Harvey K, Petasis NA, Hogg N, Brady HR: Cutting edge: lipoxins rapidly stimulate nonphlogistic phagocytosis of apoptotic neutrophils by monocyte-derived macrophages. J Immunol 2000, 164:1663-1667.

36. Maddox JF, Serhan CN: Lipoxin A4 and B4 are potent stimuli for human monocyte migration and adhesion: selective inactivation by dehydrogenation and reduction. J Exp Med 1996, 183:137-146.

37. Bannenberg GL, Chiang N, Ariel A, Arita M, Tjonahen E, Gotlinger KH, Hong S, Serhan CN: Molecular circuits of resolution: formation and actions of resolvins and protectins. J Immunol 2005 174:4345-4355.

38. Chen M, Lam BK, Kanaoka Y, Nigrovic PA, Audoly LP, Austen KF, Lee DM: Neutrophil-derived leukotriene B4 is required for inflammatory arthritis. J Exp Med 2006, 203:837-842.

39. Yacoubian S, Serhan CN: New endogenous anti-inflammatory and proresolving lipid mediators: implications for rheumatic diseases. Nature clinical practice Rheumatology 2007, 3:570-579. quiz 571 p following 589.

40. Calder PC: Polyunsaturated fatty acids, inflammatory processes and inflammatory bowel diseases. Mol Nutr Food Res 2008, 52:885-897.

41. Koletzko S, Sherman P, Corey M, Griffiths A, Smith C: Role of infant feeding practices in development of Crohn's disease in childhood. BMJ 1989 , 298:1617-1618.

42. Clavano NR: Mode of feeding and its effect on infant mortality and morbidity. J Trop Pediatr 1982, 28:287-293.

43. Takamoto M, Yano T, Shintani T, Hiraku S: A highly sensitive and selective method for the determination of Leukotriene B4 in human plasma by negative ion chemical ionization/gas chromatography/tandem mass spectrometry. J Pharm Biomed Anal 1995, 13:1465-1472.

44. Kakutani S, Ishikura Y, Tateishi N, Horikawa C, Tokuda H, Kontani M, Kawashima H, Sakakibara Y, Kiso Y, Shibata H, Morita I: Supplementation of arachidonic acid-enriched oil increases arachidonic acid contents in plasma phospholipids, but does not increase their metabolites and clinical parameters in Japanese healthy elderly individuals: a randomized controlled study. Lipids Health Dis 2011, 10:241.

45. Mas E, Croft KD, Zahra P, Barden A, Mori TA: Resolvins D1, D2, and other mediators of self-limited resolution of inflammation in human blood following n-3 fatty acid supplementation. Clin Chem 2012, 58:1476-1484 
46. Gomolka B, Siegert E, Blossey K, Schunck WH, Rothe M, Weylandt KH: Analysis of omega-3 and omega- 6 fatty acid-derived lipid metabolite formation in human and mouse blood samples. Prostaglandins Other Lipid Mediat 2011, 94:81-87.

47. Lucas A, Mitchell MD: Prostaglandins in human milk. Arch Dis Child 1980, 55:950-952.

48. Serhan CN, Savill J: Resolution of inflammation: the beginning programs the end. Nat Immunol 2005, 6:1191-1197.

49. Arita M, Yoshida M, Hong S, Tjonahen E, Glickman JN, Petasis NA, Blumberg RS, Serhan CN: Resolvin E1, an endogenous lipid mediator derived from omega-3 eicosapentaenoic acid, protects against 2,4,6-trinitrobenzene sulfonic acidinduced colitis. Proc Natl Acad Sci USA 2005, 102:7671-7676.

50. Ishida T, Yoshida M, Arita M, Nishitani Y, Nishiumi S, Masuda A, Mizuno S, Takagawa T, Morita Y, Kutsumi H, et al: Resolvin E1, an endogenous lipid mediator derived from eicosapentaenoic acid, prevents dextran sulfate sodium-induced colitis. Inflamm Bowel Dis 2010, 16:87-95.

51. Fiorucci S, Wallace JL, Mencarelli A, Distrutti E, Rizzo G, Farneti S, Morelli A, Tseng JL, Suramanyam B, Guilford WJ, Parkinson JF: A beta-oxidation -resistant lipoxin A4 analog treats hapten-induced colitis by attenuating inflammation and immune dysfunction. Proc Natl Acad Sci USA 2004, 101:15736-15741.

52. Bento AF, Claudino RF, Dutra RC, Marcon R, Calixto JB: Omega-3 fatty acidderived mediators 17(R)-hydroxy docosahexaenoic acid, aspirin-triggered resolvin D1 and resolvin D2 prevent experimental colitis in mice. J Immunol 2011, 187:1957-1969.

53. Campbell EL, MacManus CF, Kominsky DJ, Keely S, Glover LE, Bowers BE, Scully M, Bruyninckx WJ, Colgan SP: Resolvin E1-induced intestinal alkaline phosphatase promotes resolution of inflammation through LPS detoxification. Proc Natl Acad Sci USA 2010, 107:14298-14303.

54. Krishnamoorthy S, Recchiuti A, Chiang N, Yacoubian S, Lee CH, Yang R, Petasis NA, Serhan CN: Resolvin D1 binds human phagocytes with evidence for proresolving receptors. Proc Natl Acad Sci USA 2010, 107:1660-1665.

55. Lee $T H$, Horton CE, Kyan-Aung U, Haskard D, Crea AE, Spur BW: Lipoxin A4 and lipoxin B4 inhibit chemotactic responses of human neutrophils stimulated by leukotriene B4 and N-formyl-L-methionyl-L-leucyl-Lphenylalanine. Clin Sci (Lond) 1989, 77:195-203.

56. Schwab JM, Chiang N, Arita M, Serhan CN: Resolvin E1 and protectin D1 activate inflammation-resolution programmes. Nature 2007, 447:869-874

57. Prescott D, McKay DM: Aspirin-triggered lipoxin enhances macrophage phagocytosis of bacteria while inhibiting inflammatory cytokine production. Am J Physiol Gastrointest Liver Physiol 2011, 301:G487-G497.

58. Gewirtz AT, McCormick B, Neish AS, Petasis NA, Gronert K, Serhan CN, Madara JL: Pathogen-induced chemokine secretion from model intestinal epithelium is inhibited by lipoxin A4 analogs. J Clin Invest 1998, 101:1860-1869.

59. Karp CL, Flick LM, Park KW, Softic S, Greer TM, Keledjian R, Yang R, Uddin J, Guggino WB, Atabani SF, et al: Defective lipoxin-mediated antiinflammatory activity in the cystic fibrosis airway. Nat Immunol 2004, 5:388-392.

60. Dixon DL, Griggs KM, Forsyth KD, Bersten AD: Lower interleukin-8 levels in airway aspirates from breastfed infants with acute bronchiolitis. Pediatric allergy and immunology : official publication of the European Society of Pediatric Allergy and Immunology 2010, 21:e691-e696.

61. Schnabl KL, Van Aerde JE, Thomson AB, Clandinin MT: Necrotizing enterocolitis: a multifactorial disease with no cure. World journal of gastroenterology: WJG 2008, 14:2142-2161.

62. Maayan-Metzger A, Avivi S, Schushan-Eisen I, Kuint J: Human milk versus formula feeding among preterm infants: short-term outcomes. Am J Perinatol 2012, 29:121-126.

63. Xu ZZ, Zhang L, Liu T, Park JY, Berta T, Yang R, Serhan CN, Ji RR: Resolvins RvE1 and RvD1 attenuate inflammatory pain via central and peripheral actions. Nature medicine 2010, 16:592-597. 591p following 597.

64. Marangoni F, Agostoni C, Lammardo AM, Giovannini M, Galli C, Riva E: Polyunsaturated fatty acid concentrations in human hindmilk are stable throughout 12-months of lactation and provide a sustained intake to the infant during exclusive breastfeeding: an Italian study. Br J Nutr 2000, 84:103-109.

65. Lauritzen L, Hansen HS, Jorgensen MH, Michaelsen KF: The essentiality of long chain $\mathrm{n}-3$ fatty acids in relation to development and function of the brain and retina. Prog Lipid Res 2001, 40:1-94.
66. Harzer G, Haug M, Bindels JG: Biochemistry of human milk in early lactation. Z Ernährungswiss 1986, 25:77-90.

67. Lauritzen L, Carlson SE: Maternal fatty acid status during pregnancy and lactation and relation to newborn and infant status. Matern Child Nutr 2011, 7(Suppl 2):41-58

68. Koletzko B, Lien E, Agostoni C, Bohles H, Campoy C, Cetin I, Decsi T, Dudenhausen JW, Dupont C, Forsyth S, et al: The roles of long-chain polyunsaturated fatty acids in pregnancy, lactation and infancy: review of current knowledge and consensus recommendations. J Perinat Med 2008, 36:5-14.

69. Lin YH, Llanos A, Mena P, Uauy R, Salem N Jr, Pawlosky RJ: Compartmental analyses of $2 \mathrm{H} 5$-alpha-linolenic acid and $\mathrm{C}-\mathrm{U}$-eicosapentaenoic acid toward synthesis of plasma labeled 22:6n-3 in newborn term infants. Am J Clin Nutr 2010, 92:284-293.

70. Cunnane SC, Francescutti V, Brenna JT, Crawford MA: Breast-fed infants achieve a higher rate of brain and whole body docosahexaenoate accumulation than formula-fed infants not consuming dietary docosahexaenoate. Lipids 2000, 35:105-111.

71. Foreman-van Drongelen MM, al MD, van Houwelingen AC, Blanco CE, Hornstra G: Comparison between the essential fatty acid status of preterm and full-term infants, measured in umbilical vessel walls. Early human development 1995, 42:241-251

72. Uauy R, Mena P, Wegher B, Nieto S, Salem N Jr: Long chain polyunsaturated fatty acid formation in neonates: effect of gestational age and intrauterine growth. Pediatr Res 2000, 47:127-135.

73. Field CJ, Van Aerde JE, Robinson LE, Clandinin MT: Effect of providing a formula supplemented with long-chain polyunsaturated fatty acids on immunity in full-term neonates. Br J Nutr 2008, 99:91-99.

74. Field CJ, Clandinin MT, Van Aerde JE: Polyunsaturated fatty acids and T-cell function: implications for the neonate. Lipids 2001, 36:1025-1032

75. Pastor N, Soler B, Mitmesser SH, Ferguson P, Lifschitz C: Infants fed docosahexaenoic acid- and arachidonic acid-supplemented formula have decreased incidence of bronchiolitis/bronchitis the first year of life. Clin Pediatr 2006, 45:850-855.

76. Minns LM, Kerling EH, Neely MR, Sullivan DK, Wampler JL, Harris CL, Berseth $\mathrm{CL}$, Carlson SE: Toddler formula supplemented with docosahexaenoic acid (DHA) improves DHA status and respiratory health in a randomized, double-blind, controlled trial of US children less than 3 years of age. Prostaglandins Leukot Essent Fatty Acids 2010, 82:287-293.

77. Furuhjelm C, Warstedt K, Larsson J, Fredriksson M, Bottcher MF, Falth-Magnusson K, Duchen K: Fish oil supplementation in pregnancy and lactation may decrease the risk of infant allergy. Acta Paediatr 2009, 98:1461-1467.

78. Duchen K, Yu G, Bjorksten B: Atopic sensitization during the first year of life in relation to long chain polyunsaturated fatty acid levels in human milk. Pediatr Res 1998, 44:478-484.

79. Hudert CA, Weylandt KH, Lu Y, Wang J, Hong S, Dignass A, Serhan CN, Kang JX: Transgenic mice rich in endogenous omega-3 fatty acids are protected from colitis. Proc Natl Acad Sci USA 2006, 103:11276-11281.

80. Titos E, Rius B, Gonzalez-Periz A, Lopez-Vicario C, Moran-Salvador E, Martinez-Clemente M, Arroyo V, Claria J: Resolvin D1 and its precursor docosahexaenoic acid promote resolution of adipose tissue inflammation by eliciting macrophage polarization toward an M2-like phenotype. J Immunol 2011, 187:5408-5418.

81. Danielsson KN, Rydberg EK, Ingelsten M, Akyurek LM, Jirholt P, Ullstrom C, Forsberg GB, Boren J, Wiklund O, Hulten LM: 15-Lipoxygenase-2 expression in human macrophages induces chemokine secretion and $\mathrm{T}$ cell migration. Atherosclerosis 2008, 199:34-40.

82. Viita H, Sen CK, Roy S, Siljamaki T, Nikkari T, Yla-Herttuala S: High expression of human 15-lipoxygenase induces NF-kappaB-mediated expression of vascular cell adhesion molecule 1, intercellular adhesion molecule 1, and T-cell adhesion on human endothelial cells. Antioxid Redox Signal 1999, 1:83-96.

83. Moser AB, Jones DS, Raymond GV, Moser HW: Plasma and red blood cell fatty acids in peroxisomal disorders. Neurochem Res 1999, 24:187-197.

84. Yang R, Chiang N, Oh SF, Serhan CN: Metabolomics-lipidomics of eicosanoids and docosanoids generated by phagocytes. In Current protocols in immunology. Edited by John E Coligan, et al. Somerset: John Wiley \& Sons; 2011. Chapter 14:Unit 1426. 
85. Serhan CN, Nicolaou KC, Webber SE, Veale CA, Dahlen SE, Puustinen TJ, Samuelsson B: Lipoxin A Stereochemistry and biosynthesis. J Biol Chem 1986, 261:16340-16345.

86. Sun YP, Oh SF, Uddin J, Yang R, Gotlinger K, Campbell E, Colgan SP, Petasis NA, Serhan CN: Resolvin D1 and its aspirin-triggered 17R epimer. Stereochemical assignments, anti-inflammatory properties, and enzymatic inactivation. J Biol Chem 2007, 282:9323-9334.

doi:10.1186/1476-511X-12-89

Cite this article as: Weiss et al:: High levels of anti-inflammatory and proresolving lipid mediators lipoxins and resolvins and declining

docosahexaenoic acid levels in human milk

during the first month of lactation. Lipids in Health and Disease 2013 12:89.

\section{Submit your next manuscript to BioMed Central and take full advantage of:}

- Convenient online submission

- Thorough peer review

- No space constraints or color figure charges

- Immediate publication on acceptance

- Inclusion in PubMed, CAS, Scopus and Google Scholar

- Research which is freely available for redistribution 